\title{
ХИМИЯ ТВЕРДОГО ТЕЛА
}

DOI - 10.32743/UniChem.2021.83.5.11639

\section{ПЕРСПЕКТИВЫ РЕГЕНЕРАЦИИ И ГЛУБОКОЙ ПЕРЕРАБОТКИ ДЕЗАКТИВИРОВАН- НОГО ЦЕОЛИТА СаА-У В НОВЫЕ АДСОРБЕНТЫ}

\author{
Ялгашев Элмурод Яхшибой угли \\ мл. науч. сотр., \\ Узбекский химико-фармацевтический научно-исследовательский институт, \\ Республика Узбекистан, г. Ташкент \\ E-mail: chemyalgashev@mail.ru \\ Мансурова Малохат
}

канд. хим. наук, ст. науч. сотр., Узбекский химико-фармачевтический научно-исследовательский институт,

Республика Узбекистан, г. Ташкент

Исаева Нурхон Фархатовна

канд. хим. наук, Центр передовых технологии при Министерстве Инноваций, Республика Узбекистан, г. Ташкент

Шерматов Бобомирза Эибаевич канд. техн. наук, главный специалист СП «Enter Engineering Pte.ltd»,

Республика Узбекистан, г. Ташкент E-mail: babamurza.shermatov@ent-en.com

\section{PROSPECTS FOR THE REGENERATION AND DEEP PROCESSING OF DEACTIVATED CaA-U ZEOLITE INTO NEW ADSORBENTS}

\author{
Elmurod Yalgashev \\ Junior Researcher, Uzbek Chemical and Pharmaceutical Research Institute, \\ Uzbekistan, Tashkent \\ Malokhat Mansurova \\ PhD in Chemistry, Senior Researcher, Uzbek Chemical and Pharmaceutical Research Institute, \\ Uzbekistan, Tashkent \\ Nurkhon Isaeva \\ PhD in Chemistry, \\ Center for Advanced Technologies under the Ministry of Innovation \\ Uzbekistan, Tashkent \\ Bobomirza Shermatov \\ Candidate of Technical Sciences, Chief Specialist company «Enter Engineering Pte.ltd», \\ The Republic of Uzbekistan, Tashkent
}

\begin{abstract}
АННОТАЦИЯ
Рассмотрены вопросы рационального использования цеолита СаА-У, утратившего адсорбционную способность в процессе осушки природного газа из-за накопления углеродистых отложений. Методами рентгенофазового и термогравиметрического анализов доказана целесообразность термоокислительной регенерации вне адсорбера большей части отработанного цеолита. Терморегенерированная цеолитная крошка рекомендована для удаления воды из отработанных масел.
\end{abstract}

Библиографическое описание: Перспективы регенерации и глубокой переработки дезактивированного цеолита СаA-У в новые адсорбенты // Universum: химия и биология : электрон. научн. журн. Ялгашев Э.Я. [и др.]. 2021. 5(83). URL: https://7universum.com/ru/nature/archive/item/11639 
In this article considered the issues of rational use of $\mathrm{CaA}-\mathrm{U}$ zeolite, which has lost its adsorption capacity in the process of drying natural gas due to the accumulation of carbonaceous deposits. Using the methods of X-ray phase analysis and thermogravimetric analysis, the expediency of thermo-oxidative regeneration outside the adsorber of most of the spent zeolite has been proved. Thermoregenerated zeolite chips are recommended for removing water from waste oils.

Ключевые слова: газопереработка, сорбенты, цеолит, СаА, регенерация, насыпная плотность, динамическая активность.

Keywords: gas processing, sorbents, zeolite, CaA, regeneration, bulk density, dynamic activity.

Введение. Синтезу и использованию разнообразных цеолитов в сорбционных процессах посвящено множество научных исследований и прикладных работ. Неослабевающий интерес к сорбентам этого типа обусловлен широкой областью применения, способностью сохранять свою активность и селективность в течение продолжительного времени, а также восстанавливать свои свойства путем окислительной регенерации непосредственно в промышленных адсорберах [1-3]. Все же через несколько лет, в зависимости от конкретных условий эксплуатации, подобная регенерация не позволяет полноценно улучшить утраченную адсорбционную емкость и возникает необходимость замены отработанных адсорбентов [4]. Традиционные технологии производства цеолитов основаны на использовании дорогостоящих реагентов (глинозем, гидроксид алюминия, силикат-глыба, жидкое стекло, едкий натр) [5]. Отсутствие бокситового сырья и, соответственно производства гидроксида алюминия, делают нефте-газоперерабатывающую промышленность Узбекистана зависимой от импорта цеолитов.

В настоящее время с целью снижения себестоимости цеолитов и расширения сырьевой базы их производства все шире используются отходы и полупродукты других производств, а также альтернативные виды исходного сырья. Вопросы повторного использования отработанных цеолитов требуют решения не только исходя из сокращения расхода валюты на импорт, но и являются определяющими при обеспечении экологической безопасности промышленных регионов. Общепризнано, что основным источником опасности для населения и природной среды являются незамкнутые техногенные потоки вещества, создаваемые хозяйственной деятельностью, что приводит к нарушению биосферного равновесия [6]. Только предприятия Узбекистана ежегодно пополняют отвалы 600-700 тоннами отходов цеолитов различного типа, в том числе отравляющими атмосферу серосодержащими соединениями.

Инновационный подход к использованию такого типа токсичных неиспользуемых веществ, отнесенных к IV и V классам опасности [7], подразумевает два основных направления вторичного применения, которые позволят сократить пространство для их размещения и хранения, а также обеспечить ряд отраслей экономики эффективными сорбционными материалами.

Первое - это многоцелевая безопасная утилизация отработанных цеолитов, необратимо утратив- ших комплекс потребительских характеристик, необходимых в первоначальном процессе, но обладающих рядом полезных свойств для последующего применения в других областях промышленности [8]. Например, благодаря лучшей сорбционной способности, по сравнению с промышленным активированным углем КАД-иодный, адсорбенты, полученные из цеолитов отработанных в процессах нефтепереработки, могут быть использованы для извлечения и концентрирования токсичных элементов (As, $\mathrm{Pb}, \mathrm{Hg}$ ) при очистке сточных вод [9]. После регенерации, включающей очистку от механических примесей и десорбцию влаги, отработанный цеолит типа $\mathrm{NaX}$ Оренбургского газохимического комплекса, был использован при производстве бетонов и асфальтовых смесей [7]. Показано также, что переработанные таким образом адсорбенты, перспективны в практике выращивания сельскохозяйственной птицы. Положительный эффект от добавок отработанных цеолитов при производстве строительных материалов обусловлен спецификой их пористой структуры, которая позволяет связывать большие количества $\mathrm{CaO}, \mathrm{SO}_{3}$ в известковых и известково-гипсовых системах. В результате разложение цеолитов на гидросульфоалюминаты и гидросиликатный гель происходит гораздо быстрее, чем других алюмосиликатов, что улучшает качество цементных композиций [10]. Отработанный цеолит (измельченный в шаровой мельнице), являющийся отходом от установок сероочистки газов предложено применять в качестве обезвреживающего адсорбента в процессе утилизации нефтяного шлама в прочный экологически безопасный органоминеральный строительный материал, устойчивый к агрессивной окружающей среде [11]. Второе направление предусматривает разработку эффективной технологии регенерации отработанных цеолитов уже вне промышленных адсорберов в специальном оборудовании, с последующим возвратом в первоначальный процесс, а также поиск путей рациональной утилизации остатков цеолитной крошки [12-15]. Выбор направления использования отработанных цеолитов, безусловно, зависит от степени сохранности кристаллической структуры и физико-механических характеристик исследуемого вторичного сырья.

\section{Методика эксперимента}

Исследованы образцы цеолитного сорбента СаA-У, отработанные в процессе осушки природного газа на Шуртанском ГХК, отобранные из отвалов вне предприятия. Фазовый состав представительных 
проб образцов определяли на дифрактометре Дрон3. Потери веса при прокаливании исследовали с помощью дериватографа Heson HS-TGA-103 в интервале температур 25- $650{ }^{\circ} \mathrm{C}$ со скоростью нагрева $10{ }^{\circ} \mathrm{C} /$ мин. Общее содержание углерода в составе коксообразных отложений определяли, классическим методом путем сожжения навески пробы массой 1 г в кварцевой трубке в потоке кислорода при $900{ }^{\circ} \mathrm{C}$ и последующим поглощением $\mathrm{CO}_{2}$ в колонке с натронным асбестом. Анализ газов регенерации осуществляли хроматографически.

Условия термоокислительной регенерации максимально имитировали режим во вращающейся трубной печи производительностью 1000 т/год, по разработанному в УзКФИТИ способу для десорбционно-окислительной регенерации цеолитов, отработанных на промышленных установках сероочистки природного газа [13]. Технология регенерации дезактивированных образцов СаА-У предусматривает осуществление десорбции углеводородной составляющей, слабо связанной с адсорбентом, в токе инертного газа при умеренной температуре и плавное увеличение содержания кислорода для обеспечения выгорания коксообразных отложений при температуре не выше $550{ }^{\circ} \mathrm{C}$. Цеолитную крошку, из-за малых размеров не пригодную для вторичного использования в адсорбционных процессах, измельчали до порошкообразного состояния, смешивали с каолином в качестве связующего и разбавленной азотной кислотой, подбирая соотношение компонентов до получения пластичной массы. Формовкой оптимального варианта массы экструзией, с последующей сушкой и прокаливанием экструдатов, получали гранулированный адсорбента. Его адсорбционные свойства, также, как и эффективность термоокислительной обработки стационарного слоя адсорбента азотно-кислородной смесью переменного состава, оценивали по изменению значения точки росы сравнительно со свежим цеолитом.

\section{Результаты эксперимента и их обсуждение}

С целью оценки качества вторичного сырья ряд представительных проб (по 1 кг каждая), отобранных в отвалах ШГХК, фракционировали на ситах с различным размером ячеек (таблица 1). Как следует из приведенных данных, целые гранулы СаА-У диаметром 3,2 и 1,6 мм составляли от 60,35 до 90,25 \% и вполне удовлетворяли критерию прочности (таблица 2).

Таблица 1.

Гранулометрический состав отработанного СаА-у

\begin{tabular}{|c|c|c|c|c|c|c|}
\hline \multirow{2}{*}{$\begin{array}{c}\text { Номер пробы } \\
\text { при рассеве }\end{array}$} & \multicolumn{7}{|c|}{ Содержание частиц на ситах различного размера; \% } \\
\hline Проба №1 & $\mathbf{3}$ & $\mathbf{3 , 0} \div \mathbf{2 , 5}$ & $\mathbf{2 , 5} \div \mathbf{1 , 6}$ & $\mathbf{1 , 6} \div \mathbf{0 , 3 1 5}$ & $\mathbf{0 , 3 1 5 \div \mathbf { 0 , 1 6 }}$ & $\leq \mathbf{0 , 1 6}$ \\
\hline Проба №2 & 46,23 & 1,22 & 39,47 & 10,53 & 2,15 & 0,40 \\
\hline Проба №3 & 20,07 & 3,53 & 48,94 & 25,25 & 1,54 & 0,67 \\
\hline Проба №4 & 36,56 & 1,86 & 27,11 & 27,96 & 4,86 & 1,65 \\
\hline Проба №5 & 30,23 & 2,42 & 27,70 & 37,25 & 0,68 & 1,72 \\
\hline
\end{tabular}

Таблица 2.

Физико-химические и адсорбционные свойства адсорбентов

\begin{tabular}{|c|c|c|c|c|c|c|}
\hline \multirow{3}{*}{$\begin{array}{c}\text { Наименование } \\
\text { показателей }\end{array}$} & Свежий & \multicolumn{2}{|c|}{ Отработанный } & \multicolumn{2}{|c|}{ Регенерированный } & \begin{tabular}{|c} 
Полученный на \\
основе фракции \\
$1,6 \div 0,315$
\end{tabular} \\
\hline & \multicolumn{6}{|c|}{ Диаметр гранул адсорбента; мм } \\
\hline & 3,2 & 3,2 & 1,6 & 3,2 & $\mathbf{1 , 6}$ & 1,6 \\
\hline 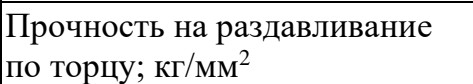 & 14,2 & 9,36 & 8,8 & 9,76 & 8,8 & 11,9 \\
\hline 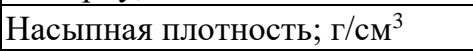 & 0,8 & 0,88 & 0,88 & 0,69 & 0,69 & 0,77 \\
\hline Суммарный объем пор; см$^{3} / \Gamma$ & 0,46 & 0,40 & 0,33 & 0,39 & 0,35 & 0,31 \\
\hline Удельная поверхность; м²/г & 240,0 & 145,5 & 136,1 & 220,0 & 220,0 & 230,0 \\
\hline 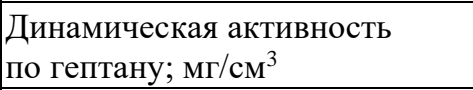 & 57,5 & 39,4 & 50,8 & 55,0 & 47,2 & 55,1 \\
\hline 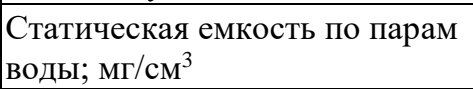 & 150,0 & 125,6 & 115,7 & 141,4 & 143,5 & 51,4 \\
\hline 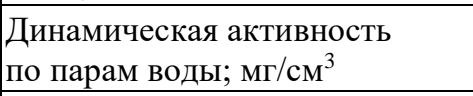 & 110,2 & 77,0 & 93,0 & 107,5 & 110,0 & 37,7 \\
\hline Точка росы; ${ }^{\circ} \mathrm{C}$ & -60 & -23 & -27 & -52 & -54 & -56 \\
\hline
\end{tabular}




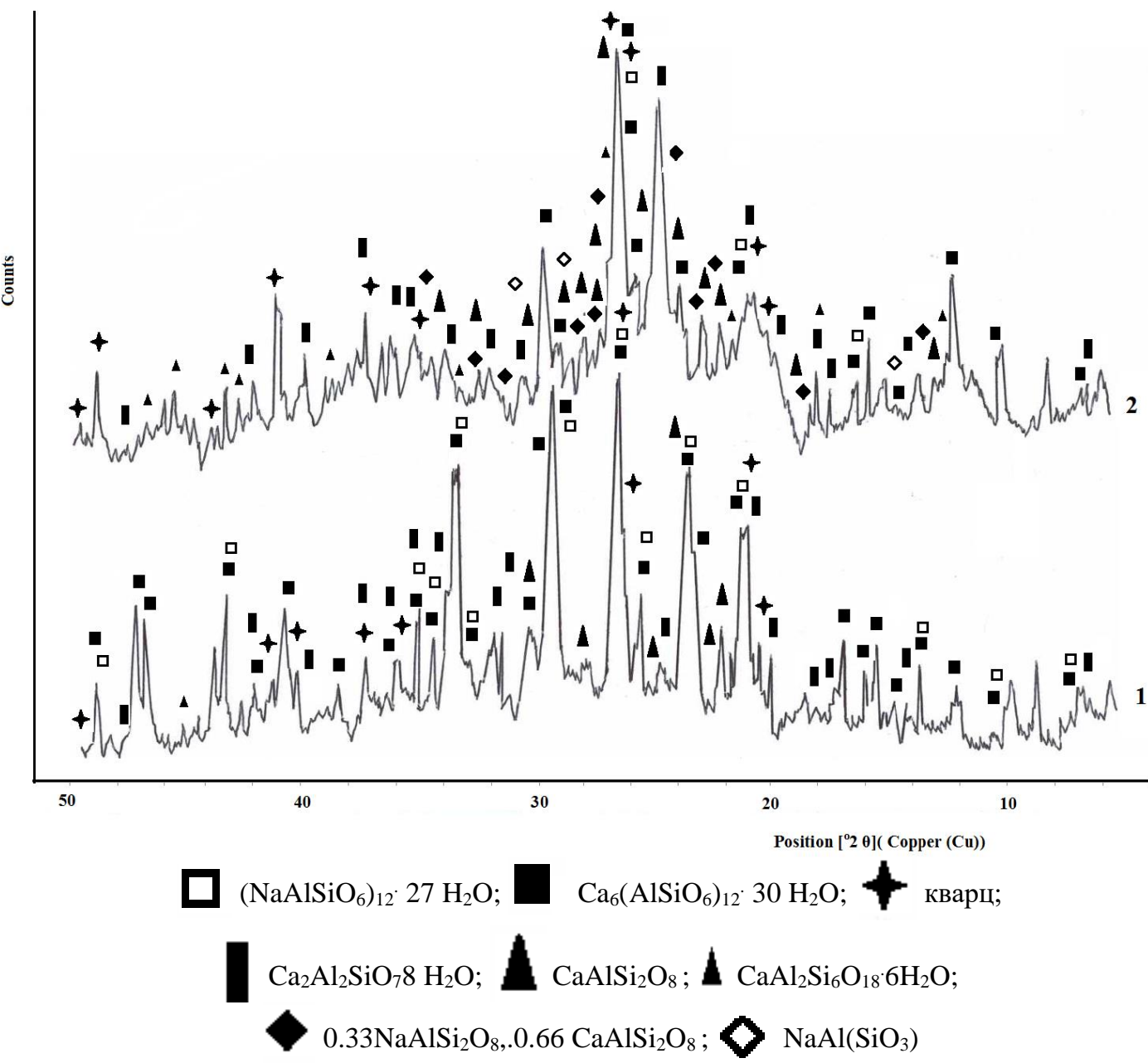

Рисунок 1. Дифрактограммы: 1 - свежсего цеолита СаА-У; 2 - нового цеолитного адсорбента, синтезированного из крошки отработанного СаА-У и каолина

Как следует из рисунка 1, в дифрактограмме свежего цеолита СаА-У наблюдаются практически все линии, соответствующие кристаллической

форме соединения $\mathrm{Ca}_{6}\left(\mathrm{AlSiO}_{6}\right)_{12} \cdot 30 \quad \mathrm{H}_{2} \mathrm{O}$ (согласно картотеке ASTM), то есть цеолиту СaA, частично перекрывающиеся очень близкими линиями от $\left(\mathrm{NaAlSiO}_{6}\right)_{12} \cdot 27 \mathrm{H}_{2} \mathrm{O}$.

Однако, соотношение интенсивности линий сильно отличалось от характерных для классической формы цеолитов типа СaA и $\mathrm{NaA}$. В дифрактограмме чистого цеолита СаА максимальную интенсивность имеет линия, соответствующая межплоскостному расстоянию $\mathrm{d}=12.2 \AA$, относительно которой две другие характеристичные линии (подчеркнуты) с $\mathrm{d}=\underline{8.66}$ и $3.28 \AA$ составляют $40 \%$. В дифрактограмме свежего цеолита СаА-У (рис. 1, дифрактограмма №1) наблюдались следующие линии, отнесенными нами к проявлению соединения $\mathrm{Ca}_{6}\left(\mathrm{AlSiO}_{6}\right)_{12} \cdot 30 \mathrm{H}_{2} \mathrm{O}: \mathrm{d}=\underline{12.2}(\underline{13})$; 8.65(16); 7.08(18); 6.12(14); 5.48(28); 5.02(12); $4.08(62) ; 3,93(33), 3.696(77) ; 3.276(98) ; 2.977(100)$; 2.876 (46); 2.74(27); 2.614 (55); 2.502(44);2.452(24); $2.359(20) ; 2.237$ (10); 2.166(36); 2.14(16); 2.103(19); $2.074(13) ; 2.04(36), 1.914(14) ; 1.89(35) \AA . *$ Здесь и далее после значения межплоскостного расстояния $\mathrm{d}$ в скобках указана относительная интенсивность наблюдаемых линий в процентах от наиболее интенсивной линии наблюдаемой в дифрактограмме.
В отработанных образцах цеолита СаА-У линии с $\mathrm{d}=3.349(100) ; 2.12(8) ; 2.083(11) ; 2.023 \AA$ на дифрактограмме №3 рисунка 2 позволяют идентифицировать графитизированный углерод. При этом степень зауглероживания порошкообразной фракции отработанного СаА-У, была намного выше, чем крупной крошки или целых гранул, в дифрактограмме №2 которых, лишь две линии с d=3.345 (47) и 1.97(5) $\AA$ можно отнести к кристаллической модификации углерода. В дифрактограммах термообработанных образцов линии углерода полностью исчезали.

В дифрактограммах (рис. 2) как отработанных, так и терморегенерированных адсорбентов также присутствовало большинство линий, соответствующих $\mathrm{Ca}_{6}\left(\mathrm{AlSiO}_{4}\right)_{12} \cdot 30 \mathrm{H}_{2} \mathrm{O} \mathrm{c} \mathrm{d}=12.2 ; 7.08 ; 6.12 ; 4.08$; $3.53 ; 3.39 ; 3.276 ; 2.675 ;$ и $2.50 \AA$, хотя более ярко проявлялись линии от натриевой формы цеолита$\left(\mathrm{NaAlSiO}_{6}\right)_{12} \cdot 27 \mathrm{H}_{2} \mathrm{O}$. А именно линии с $\mathrm{d}=12.3 ; 7.11$; $5.51 ; 4.11 ; 3.714 ; 3.417 ; 3.293 ; 2.987 ; 2.754 ; 2.626$; $2.515 ; 2.177 ; 1.924 \AA$.

Этот факт указывает на сохранение кристаллической структуры цеолитов типа «А», характерной для свежего образца, во время длительной эксплуатации цеолита СаА-У в промышленном адсорбере, его пребывании в отвале и выбранных условиий термоокислительной регенерации. 


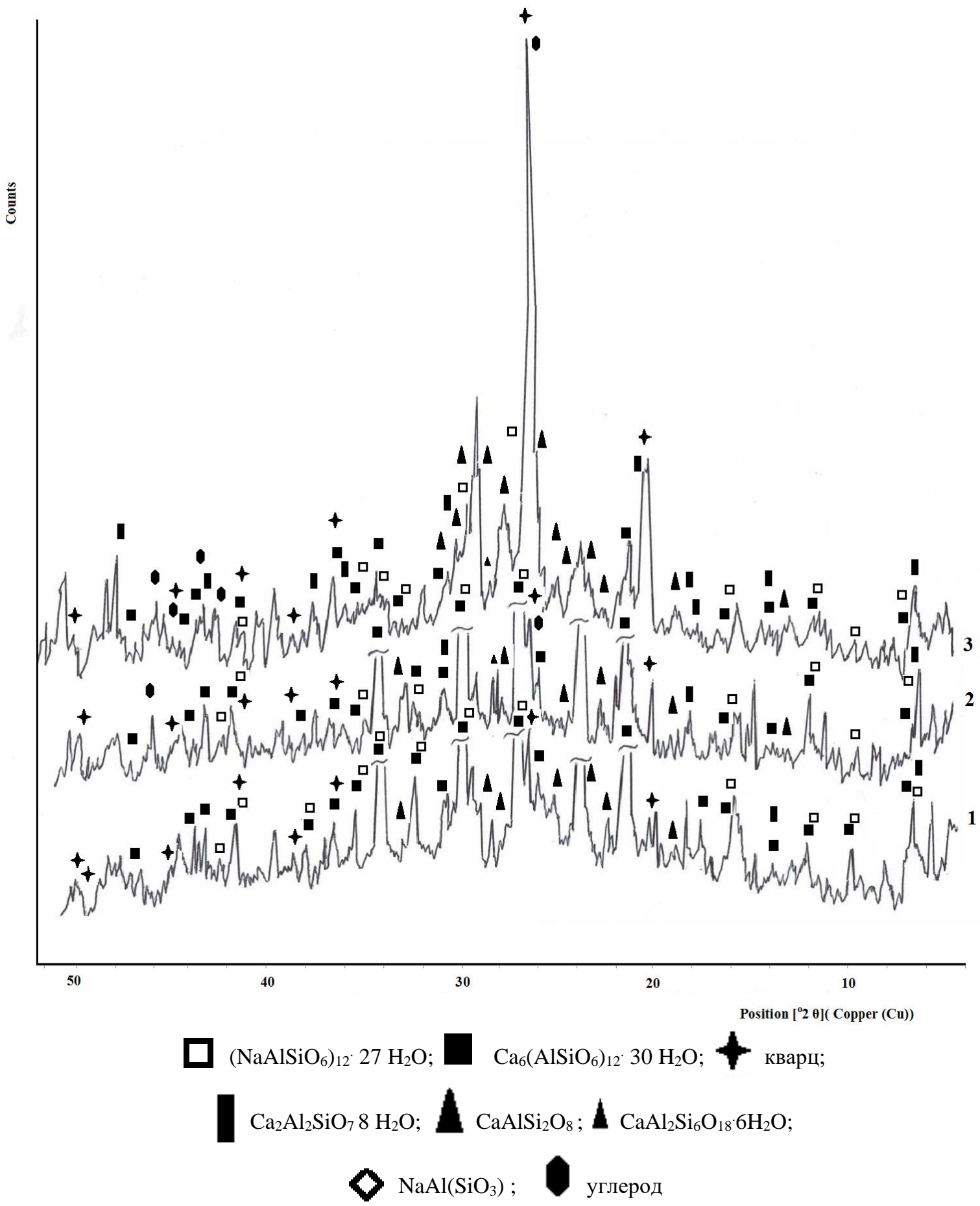

Рисунок 2. Дифрактограммы: 1 - регенерированного цеолита СаА-У, фракция более 0.16 мм; 2 - отработанного цеолита СаА-У, фракция более 0.16 мм; 3 - отработанного цеолита СаА-У, фракция менее 0.16 мм.

Специфической особенностью всех отработанных и регенерированных образцов СаА-У также является очень низкая интенсивность одной из основных линий цеолитов типа «А» с межплоскостным расстоянием 12,2-12,3 А, по сравнению с остальными характеристическими линиями чистых цеолитов $\mathrm{CaA}$ и $\mathrm{NaA}$ (рис 1, 2). Появление дополнительных линий, соответствующих различным модификациям кристаллического $\mathrm{SiO}_{2}(\mathrm{~d}=4.36-4.34 ; 4.26 ; 3.417$; $3.34 ; 2.50 ; 2.45 ; 2.323 ; 2.177 ; 2.107 ; 2.01 ; 1.8396$; 1.837 ; $1.81-1.82 \AA)$, а также кальций алюмосиликатам с различным содержанием кристаллизационной воды, вероятно обусловлено примесными минералами в составе связующего вещества, которое было использовано для промышленного синтеза исходного цеолита СаА-У. Отдельные линии от кальций алюмосиликатов не цеолитной природы: $\mathrm{Ca}_{2} \mathrm{Al}_{2} \mathrm{SiO}_{7} \cdot 8 \mathrm{H}_{2} \mathrm{O}$ $(\mathrm{d}=12.6-12.59 ; 6.28 ; 4.285 ; 4.18 ; 4.14 ; 3.53-3.52 ; 3.04$; $2.875 ; 2.729 ; 2.613 ; 2.489 ; 2.448 ; 2.397 ; 2.368 ; 2.125$; $2.088 ; 1.89 ; 1.837 \AA), \mathrm{CaAl}_{2} \mathrm{Si}_{6} \mathrm{O}_{18} \cdot 6 \mathrm{H}_{2} \mathrm{O}(\mathrm{d}=7.14(11)$; $4.96(25) ; \quad 4.14(40) ; \quad 4.07(10) ; \quad 3.14(50) ; \quad 2.332(5)$; $2.123(5) ; 1.987(5) ; 1.783(15) \AA)$ и $\mathrm{CaAlSi}_{2} \mathrm{O}_{8}(\mathrm{~d}=6.56$; $4.70 ; 4.04 ; 3.92 ; 3.78 ; 3.46 ; 3.40 ; 3.26 ; 3.20-3.199 ; 3.18$; 
$3.3029 ; 2.93 ; 2.89 ; 2.65 \AA)$ наблюдались в дифрактограммах всех изученных образцов. Однако, в терморегенерированном образце (рис. 2, дифрактограмма № 1) и вновь синтезированном из смеси крошки и каолина (рис. 1, дифрактограмма № 2) среди кальцийалюмосиликатов преобладала безводная кристаллическая модификация - $\mathrm{CaAlSi}_{2} \mathrm{O}_{8}$.

В составе вновь синтезированного образца идентифицированы и другие алюмосиликаты. На присутствие алюмосиликата натрия состава $\mathrm{NaAl}\left(\mathrm{SiO}_{3}\right)$ указывают линии с $\mathrm{d}=3.26$ (22); 3.1(30); 2.92 (35); 2.83(22) А̊, а набор линий с d= 6.499(30); 4,04(40); $3.889(38), 3.64(35) ; 3.37(40) ; 3.0293(31)$ и $2.5146(45) \AA$, отнесен исключительно к смешанному натрийкальциевому алюмосиликату $-0.33 \mathrm{NaAlSi}_{2} \mathrm{O}_{8} \cdot 0.66$ $\mathrm{CaAlSi}_{2} \mathrm{O}_{8}$

\section{Анализ результатов исследования}

Анализ дериватограмм и состава газов, выделяющихся при прокаливании дезактивированных цеолитов, выявил, что целые гранулы СаА-У, как и их осколки размером более 1,6 мм, содержат преимущественно адсорбированную воду, 70-80 \% которой удаляется в начальный период подъема температуры до $200^{\circ} \mathrm{C}$. В указанном диапазоне температур при условии дефицита кислорода, общая потеря массы составила 12.4 \% масс., из которых на долю легко десорбируемых углеродсодержащих соединений приходилось не более 3 \% масс. Основное количество (11.9\%) достаточно прочно адсорбированных углеродсодержащих веществ десорбировалось и выгорало в интервале температур $250-470^{\circ} \mathrm{C}$ уже в воздушной атмосфере.

Отсюда следует вывод, что основная масса отработанного цеолита СаА-У, согласно данным таблицы 1 не менее $98 \%$, содержит легко окисляемые коксовые отложения. Потери при прокаливании выше предельной температуры стабильности сорбентов этого типа цеолитов - от 550 до $650{ }^{\circ} \mathrm{C}$ едва достигали $0,1 \%$ масс. от исходного образца. Содержание сернистых соединений в газах регенерации не превышало 3 - 4 масс. \%, в пересчете на $\mathrm{SO}_{2}$. Для крупных осколков гранул размером 1,6 $\div 0,315$ мм были получены близкие результаты: при нагревании до $200^{\circ} \mathrm{C}$ испарение физически адсорбированной воды обуславливало 9.8 \% потерь от исходной массы образца, а 2,3 \% приходилось на десорбцию низкомолекулярных углеводородов. Следует отметить, что углеродсодержащие соединения в крупных осколках окислялись труднее, чем в целых гранулах, и активно выгорали при $330-520{ }^{\circ} \mathrm{C}$ с выделением $\mathrm{CO}$ и $\mathrm{CO}_{2}$ с потерей веса в указанном интервале температур $2.9 \%$.

Аналогичные эксперименты с отсевом фракции менее 0,16 мм показали, что в её составе содержалось не более $6 \%$ легко удаляемой воды, а при нагревании до $200^{\circ} \mathrm{C}$ практически не десорбировались органические соединения (потеря веса менее 0,5 \% масс.). Наиболее интенсивное выгорание углеродсодержащих веществ в составе порошкообразной фракции дезактивированного СаА-У происходило выше $550^{\circ} \mathrm{C}$, потеря массы в интервале температур 550-650 ${ }^{\circ} \mathrm{C}$ достигала 4.8 \% масс. Данные рентгенофазового анализа подтверждают этот вывод, поскольку кристаллический углерод с линиями (d=3,348; 2,116; 2,08 и 1,96 А⿱), как известно, отличающийся от рентгеноаморфных коксообразных отложений высокой термостабильностью [17], однозначно идентифицирован только в составе самой мелкой фракции отработанного СаА-У. Действительно в дифрактограмме порошкообразной фракции линии, соответствующие цеолиту типа «А», отличались меньшей интенсивностью, а количество и интенсивность линий от примесных минералов, наоборот, возрастали. По-видимому, в процессе длительной эксплуатации накопление трудно удаляемых коксообразных отложений с постепенным переходом в графит, происходило, в первую очередь на границе раздела фаз цеолита и связующего. Во время эксплуатации в циклическом режиме «адсорбция-десорбция» при умеренной температуре адсорбированные углеводороды полностью не удалялись, а подвергались термодинамически предопределенному уплотнению [17]. Как следствие, в результате длительной графитизации уплотнений адсорбированных углеводородов в поровом пространстве гранул, постепенно ослаблялась связь между крупными частицами цеолита. Хранение в отвале также способствовало осыпанию «графитизированных прослоек», в совокупности с фрагментами связующих минералов. Поэтому в массе отработанного цеолита образовывалось от 2 до $6 \%$ масс. мелкой крошки, состоящей из осколков гранул и частиц с повышенным содержанием углерода. Эта часть отработанного СаА-У была признана неперспективной для получения нового цеолита. Отсев отработанного цеолита размером 0.16 мм и менее нашел применение в качестве добавки при приготовлении адсорбента защитного слоя [18]. Основной функцией этого адсорбента является поглощение избыточного кислорода из потока сероводородсодержащего газа, поступающего на вторую ступень процесса получения серы по методу Клауса.

Более 60 \% отработанного цеолита, приемлемых для дальнейшей эксплуатации размеров (более 1.6 мм), после термоокислительной обработки в удовлетворительной степени восстановили важнейшие физикохимические характеристики (таблица 2) и адсорбционные свойства при поглощении $\mathrm{H}_{2} \mathrm{O}$ и $\mathrm{H}_{2} \mathrm{~S}$ из газовых потоков. Поэтому подлежат регенерации на созданной нами вращающейся печи для регенерации цеолитов, отработанных в процессе сероочистки [14] и последующей эксплуатации в промышленных условиях.

Показана принципиальная возможность использования отхода в виде крошки цеолита (около $35 \%$ от массы отработанного цеолита (аА-У) в качестве сырья для создания нового адсорбента для осушки природного газа. Из таблицы 2 видно, что механическая прочность и удельная поверхность указанного адсорбента вполне соответствуют нормативным показателям для цеолитов и практически не отличаются от образцов регенерированных гранул отработанного СаА-У. Низкая динамическая активность при удалении паров воды, но высокая в поглощении гептана, свидетельствует о формировании достаточно развитой системы мелких пор с гидрофобными свойствами, при малом количестве транспортных пор. 
Гидрофобность поверхности пор с радиусом около 2 нм может быть следствием неполного выгорания коксообразных отложений на цеолитной крошке, смешанной с каолином. Планируются дальнейшие исследования для усовершенствования текстуры нового адсорбента с использованием цеолитной крошки путем введения в формовочную массу порообразователей и/или пластификаторов. Характерно, что испытание нового адсорбента в процессе осушки отработанного масла выявило его способность к удалению воды из водно-масляной эмульсии. Количество поглощенной воды достигало 15 \% от веса исходного образца. Поэтому указанный образец рекомендуется в качестве осушителя в процессе регенерации отработанных масел.

Таким образом, найдены варианты практически безотходной технологии переработки цеолита $\mathrm{CaA}-\mathrm{У}$, предусматривающей производство регенерированного цеолита, с динамическая активность, которого уступает свежему не более, чем на $0.5 \%$. Намечены пути рационального использования цеолитной крошки из разрушенных в процессе эксплуатации гранул СаА-У.

\section{Список литературы:}

1. Omorogie M.O, Babalola J.O. Regeneration strategies for spent solid matrices used in adsorption of organic pollutants from surface water: a critical review//Desalination and water treatment. - 2016. - № 57.-p. 518-544.

2. Melkon Tatliera, Ciğdem Atalay-Orala. Crystallization of zeolite A coatings from natural zeolite. Materials research. 2016; 19(6): 1469-1477. Doi: 10.1590/1980-5373-mr-2016-0564

3. LataS., Singh P.K. Regeneration of adsorbents and recovery of heavy metals: a review int. J. Environ. Sci. Technol. 2015. - №12.--c.1461-1478.

4. Сайпуллаев Ф.С., Хайитов Р.Р. Регенерация отработанного синтетического цеолита СаА и его характеристики // Молодой ученый. - 2015. - №8. С. 298-301.

5. Мылтыкбаева Л.А. Технология получения цеолитов из зол ТЭЦ. Энерготехнологии и ресурсосбережение. 2009. № 6 . С. 49-52.

6. Горлова О.Е. Адаптационный подход, как основание разработки технологий комплексного освоения техногенного минерального сырья, и реабилитации нарушенных территорий горнопромышленных регионов. // Плаксинские чтения - 2017, Красноярск, 12-15 сентября 2017. Сборник докладов. С. 351.

7. Береговая Н.Г., Герасименко В.В., Молчанов С.А., Морозов М.М. Перспективы вторичного использования отработанного цеолита типа $\mathrm{NaX}$ Оренбургского газохимического комплекса. //Вестник Оренбургского Государственного Университета. 2015. №10(185). С.334-336.

8. Поконова Ю.В., Олейник М.С. Технология многоцелевой утилизации отработанных цеолитов нефтепереработки. //Санкт-Петербургский Государственный Технический Университете. 2007. Т. 84. № 6. С. $309-316$.

9. Поконова Ю.В. Адсорбенты из отработанных цеолитов. // Химия твердого топлива. 2012. №3. С. $42-48$.

10. Обуздина М.В., Руш Е.А. Способы утилизации отработанных сорбентов на основе цеолитов в строительные материалы. Современные технологии. Системный анализ. Моделирование. №3. (43). 2014. С. 158-165.

11. Патент 2638019 Российская Федерация, МПКВ 09В 3/00. Способ Обезвреживания и утилизации нефтесодержащего шлама. Акопова Г.С.,Ишков А.Г., Стрекалова Л.В.- 2017111173; заявл. 03.04. 2017; опубл. 11.12. 2017. -7 c.

12. Муталов Ш.А., Ниязова М.М., Ниязов Д.Б. Регенерация отработанных цеолитов газоперерабатывающей промышленности. // UNIVERSUM. - 2019. - №11 (65). - С. 32-34.

13. Патент на способ термодесорбционно-окислительной регенерации отработанных цеолитов. Патент UZ № 02565 от 13.12.2004 г.

14. Шерматов Б.Э., Мансурова М.С., Ялгашев Э.Я. Курбанов Э.Н., Исматов Д.Н. Регенерация отработанного цеолита на опытно-промышленной установке. // Наука среди нас. 2018. 3 (7). С. 69-75.

15. Shaobin, Wang. Physical and chemical regeneration of zeolitic adsorbents for dye removal in waste water treatment / Wang Shaobin, Li Huiting, Xie Sujuan, Liu Shenglin, Xu Longya // Chemosphere. - 2006. - vol. 65. - p. 82 - 87.

16. Jin-Young, Jung. Enhanced ammonia nitrogen removal using consistent biological regeneration and ammonium exchange of zeolite in modified SBR process / Jung Jin-Young, Chung Yun-Chul, Shin Hang-Sik, Son. Dae-Hee // Water research. - 2004. - vol. 38. - p. 347 - 354.

17. Алиев А.М., Османова И.И., Сафаров А.Р., Гусейнова А.М. Особенности протекания каталитических процессов в условиях нестационарной активности катализатора. // Азербайджанский химический журнал.- 2016.- №1. C. 6-34.

18. Ялгашев Э.Я., Артукова Г.Ш., Джалалова Ш.Б., Тешабаев 3.А., Мансурова М.С. Перспективы переработки алюмосодержащих отходов в адсорбенты для процессов сероочистки. // Международная конференция «Наука и инновации». Ташкент. 26 ноября 2020 г. 2 часть. С. 166-167. 